\title{
Autothermal chemical looping reforming process of different fossil liquid fuels
}

\author{
E. García-Díez, F. García-Labiano*, L.F. de Diego, A. Abad, P. Gayán, \\ J. Adánez
}

Department of Energy and Environment, Instituto de Carboquímica (ICB-CSIC), Miguel Luesma Castán 4, E-50018 Zaragoza, Spain

\section{A R T I C L E I N F O}

Article history:

Received 13 October 2016

Received in revised form

16 December 2016

Accepted 22 December 2016

Available online $\mathrm{xxx}$

Keywords:

Hydrogen production

$\mathrm{CO}_{2}$ capture

Chemical-looping reforming

Oxygen-carrier

Liquid fuels

\begin{abstract}
A B S T R A C T
The autothermal Chemical-Looping Reforming (a-CLR) is a process where syngas is produced with two main advantages; there are captured $\mathrm{CO}_{2}$ emissions and the heat required for the syngas production is generated by the process itself. A Ni-based material is used as oxygen carrier circulating between two fluidized bed reactors: the fuel and air reactors. In this work, the auto-thermal conditions in a global $\mathrm{H}_{2}$ production process, integrated by the a-CLR process and a Water Gas Shift reactor, using different liquid fossil fuels were theoretically determined. The hydrogen production per mol of carbon in the fuel was similar for all fossil fuels, taking a value of 2.2 at the optimal operating temperature $\left(700{ }^{\circ} \mathrm{C}\right.$ ). In addition, the possibility of working at low temperature for a maximum $\mathrm{H}_{2}$ production was experimentally demonstrated in a continuous $1 \mathrm{~kW}_{\text {th }}$ a-CLR unit.

@ 2016 Hydrogen Energy Publications LLC. Published by Elsevier Ltd. All rights reserved.
\end{abstract}

\section{Introduction}

The main energy source in the world nowadays and, based on estimations, in the next decades will be petroleum with the $36 \%$ of the global sources production [1]. The oil production process in a refinery requires considerable amounts of heat and hydrogen $\left(\mathrm{H}_{2}\right)$ [2]. Consequently, large amount of $\mathrm{CO}_{2}$ are emitted in oil refineries in the furnaces and boilers for fuel feeding, cracking and reforming reactions. Focusing on the hydrogen used in the refining process, it is used in two specific and overriding processes. The first one is the hydrotreating or hydrodesulfurization process, where the sulphur, and a lesser degree of nitrogen, is removed. The second one is the hydrocracking process, where the use of $\mathrm{H}_{2}$ allows breaking carbon chains, obtaining light hydrocarbons $[2,3]$.

The linked problem is that $\mathrm{H}_{2}$ is an energetic vector that needs to be obtained from primary energy sources. In a refinery, catalytic reforming using low-boiling liquid fuels [4] and steam methane reforming (SMR) are the most common processes to obtain $\mathrm{H}_{2}$, with the disadvantage that almost $7 \mathrm{~kg}$ of $\mathrm{CO}_{2}$ per $\mathrm{kg}$ of $\mathrm{H}_{2}$ are produced and emitted into the atmosphere in the last case [5]. Therefore, the integration of a specific carbon capture and storage (CCS) technology, such as the autothermal chemical looping reforming (a-CLR), to produce $\mathrm{H}_{2}$ without $\mathrm{CO}_{2}$ emissions in the refining process represent a quiet interesting and promising alternative. The use of waste heavy liquid fuels obtained from the crude

\footnotetext{
* Corresponding author. Fax: +34 976733318.

E-mail address: glabiano@icb.csic.es (F. García-Labiano).
} 
transformation would be the preferred hydrogen source. Not only it would be possible to reduce the environmental problems but also the economic penalties associated with the refining and $\mathrm{H}_{2}$ production processes [6-8].

The a-CLR process was initially proposed by Mattison and Lyngfelt [9] as a hydrogen production process with no $\mathrm{CO}_{2}$ emissions to the atmosphere and no external heat required for the process. It is based on the partial oxidation of the fuel by oxygen which is transferred by an oxygen carrier avoiding the direct contact between air and fuel. The oxygen carrier is composed by a metal oxide and an inert support. Ni-based oxygen carriers are the most usual materials used in CLR processes [8,10-14]. Some authors have also determined that the inert support used has an important effect on the oxygen carrier behavior $[15,16]$. The CLR process is based in the use of two interconnected fluidized bed reactors. In the Fuel reactor (FR), the oxygen carrier is reduced and the fuel is partially oxidized and reformed to produce the syngas. In the Air reactor (AR), the reduced solid material is regenerated with the oxygen from the air.

The main reactions which take place in the FR are endothermic, which means that external heat is required. In the aCLR process this heat is provided by the hot oxygen carrier transferred from the AR to the FR. This oxygen carrier is heated by the exothermic regeneration reaction that takes place in the AR [13].

Another specific advantage of the a-CLR process is the possibility of obtaining pure $\mathrm{N}_{2}$ at the outlet stream of the AR by controlling the amount of air fed into the AR [17].

Although the main experience of obtaining $\mathrm{H}_{2}$ by the CLR process is with gaseous fuels [8,18], liquid fuels are becoming more relevant in the last years, being evaluated ethanol $[17,19]$, glycerol [20], free sulphur kerosene [21], and biomass pyrolysis oils [22].

The objective of this work was to determine the autothermal conditions of syngas $/ \mathrm{H}_{2}$ production in a global process including the a-CLR system and a Water Gas Shift (WGS) reactor, using different fossil fuels. Diesel and mineral oil were selected as a first step to further studies with heavy oils and waste oil produced in the refining processes. Mass and heat balances were done to analyze the effect of the different operational conditions such as oxygen-to-fuel and water-tofuel molar ratios. It was also evaluated the viability of the aCLR process in a $1 \mathrm{~kW}_{\text {th }}$ continuous unit at low temperatures to maximize hydrogen production.

\section{Theoretical calculation of the a-CLR process}

\section{Liquid fuels}

Two different liquid fossil fuels have been selected for the theoretical evaluation of the a-CLR process: diesel and mineral oil. Fig. 1 shows the distillation curve obtained for both liquid fuels. Both fuels are a mix of several paraffin's and aromatic hydrocarbons containing only carbon and hydrogen atoms, with carbon numbers ranging from approximately C7-C20 and C13-C25 for the diesel and mineral oil, respectively. Based on the elemental analysis and the distillation curves,

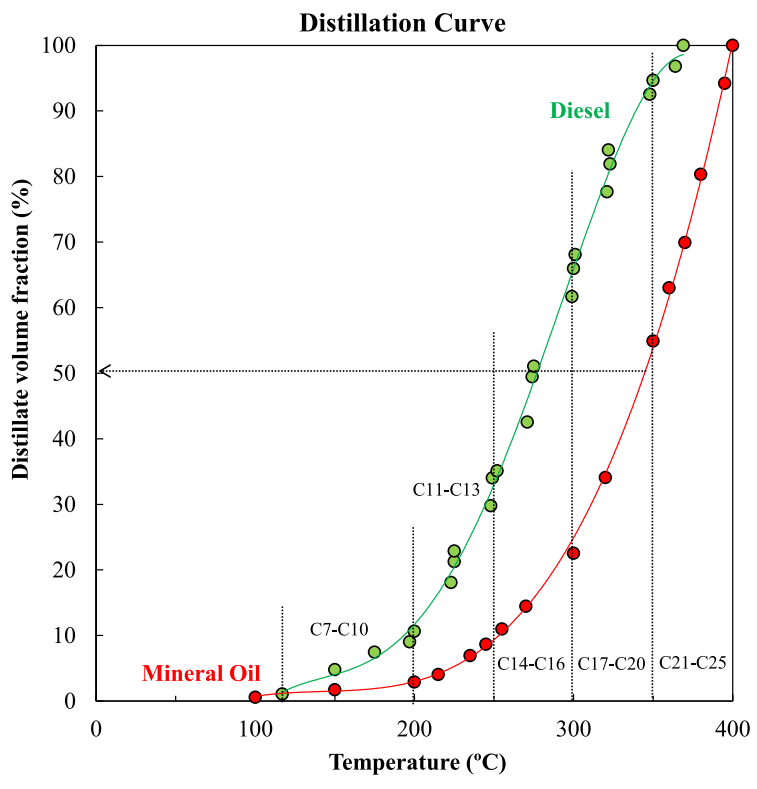

Fig. 1 - Distillation curves of the diesel and the mineral oil evaluated in this work.

the 1-Pentadecyne $\left(\mathrm{C}_{15} \mathrm{H}_{28}\right)$ and the 1-Nonadecene $\left(\mathrm{C}_{19} \mathrm{H}_{38}\right)$ were chosen as representative hydrocarbons for the diesel and the mineral oil respectively.

Table 1 shows the main reactions taking place in both the fuel and air reactors. A Ni-based material was considered as oxygen carrier due to its catalytic properties regarding reforming reactions.

To better understanding the process operation, Fig. 2 shows the gaseous products obtained in the thermodynamic equilibrium as a function of the $\mathrm{O}_{\mathrm{NiO}} /$ Fuel molar ratio using diesel as an example. It must be considered that the $\mathrm{O}_{\mathrm{NiO}} / \mathrm{Fuel}$ molar ratio is the main parameter affecting the CLR process since determines the oxygen fed into the Fuel reactor. These results were obtained using the HSC Chemistry 6.1 software [24].

Using diesel as fuel, an $\mathrm{O}_{\mathrm{NiO}} /$ Fuel molar ratio equal or higher than 44 implies that the reaction that takes place in the FR is the complete fuel oxidation reaction (R.1). If the $\mathrm{O}_{\mathrm{NiO}} /$ Diesel molar ratio is lower than 44 and higher than 15, the partial oxidation (R.6) and reforming reactions of the fuel ((R.8-R.9), (R.13)) and other possible intermediates, such as methane ((R.12), (R.15)) show up, increasing the syngas production. If the $\mathrm{O}_{\mathrm{NiO}} /$ Diesel molar ratio takes values lower than 15 there is not enough oxygen for syngas production and carbon formation reaction would take place (R.16). The behavior with the Mineral Oil is similar to the Diesel based on the reactions shown in Table 1.

The reduced oxygen carrier is transferred form the FR to the AR to be regenerated with air according to the reaction (R.21). In the case of carbon formation in the FR, it will be transferred with the oxygen carrier to the AR where the carbon combustion would produce $\mathrm{CO}_{2}$ (R.22), which will produce a decreasing in the $\mathrm{CO}_{2}$ capture efficiency. The reactions scheme above described would be similar for other fossil fuels. 
Table 1 - Main reactions in the CLR process for diesel and mineral oil. Enthalpy data taken from Barin [23].

$\Delta \mathrm{H}_{900}{ }^{\circ} \mathrm{C}(\mathrm{kJ} / \mathrm{mol})$

\begin{tabular}{|c|c|c|}
\hline \multicolumn{3}{|l|}{ Fuel reactor } \\
\hline \multicolumn{3}{|l|}{ Complete oxidation } \\
\hline $\mathrm{C}_{15} \mathrm{H}_{28}+44 \mathrm{NiO} \rightarrow 44 \mathrm{Ni}+15 \mathrm{CO}_{2}+14 \mathrm{H}_{2} \mathrm{O}$ & 989.8 & (R.1) \\
\hline $\mathrm{C}_{19} \mathrm{H}_{38}+57 \mathrm{NiO} \rightarrow 57 \mathrm{Ni}+19 \mathrm{CO}_{2}+19 \mathrm{H}_{2} \mathrm{O}$ & 1468.2 & (R.2) \\
\hline $\mathrm{CH}_{4}+4 \mathrm{NiO} \rightarrow 4 \mathrm{Ni}+\mathrm{CO}_{2}+2 \mathrm{H}_{2} \mathrm{O}$ & 135.6 & (R.3) \\
\hline $\mathrm{H}_{2}+\mathrm{NiO} \rightarrow \mathrm{Ni}+\mathrm{H}_{2} \mathrm{O}$ & -14.3 & (R.4) \\
\hline $\mathrm{CO}+\mathrm{NiO} \rightarrow \mathrm{Ni}+\mathrm{CO}_{2}$ & -48.5 & (R.5) \\
\hline \multicolumn{3}{|l|}{ Partial oxidation } \\
\hline $\mathrm{C}_{15} \mathrm{H}_{28}+15 \mathrm{NiO} \rightarrow 15 \mathrm{Ni}+15 \mathrm{CO}+14 \mathrm{H}_{2}$ & 1938.8 & (R.6) \\
\hline $\mathrm{C}_{19} \mathrm{H}_{38}+19 \mathrm{NiO} \rightarrow 19 \mathrm{Ni}+19 \mathrm{CO}+19 \mathrm{H}_{2}$ & 2688.7 & (R.7) \\
\hline \multicolumn{3}{|l|}{ Steam reforming catalyzed by $\mathrm{Ni}$} \\
\hline $\mathrm{C}_{15} \mathrm{H}_{28}+15 \mathrm{H}_{2} \mathrm{O} \rightarrow 15 \mathrm{CO}+29 \mathrm{H}_{2}$ & 2158.7 & (R.8) \\
\hline $\mathrm{C}_{15} \mathrm{H}_{28}+30 \mathrm{H}_{2} \mathrm{O} \rightarrow 15 \mathrm{CO}_{2}+44 \mathrm{H}_{2}$ & 1634.9 & (R.9) \\
\hline $\mathrm{C}_{19} \mathrm{H}_{38}+19 \mathrm{H}_{2} \mathrm{O} \rightarrow 19 \mathrm{CO}+38 \mathrm{H}_{2}$ & 2967.3 & (R.10) \\
\hline $\mathrm{C}_{19} \mathrm{H}_{38}+38 \mathrm{H}_{2} \mathrm{O} \rightarrow 19 \mathrm{CO}_{2}+57 \mathrm{H}_{2}$ & 2303.8 & (R.11) \\
\hline $\mathrm{CH}_{4}+\mathrm{H}_{2} \mathrm{O} \rightarrow \mathrm{CO}+3 \mathrm{H}_{2}$ & 229.6 & (R.12) \\
\hline \multicolumn{3}{|l|}{ Dry reforming catalyzed by $\mathrm{Ni}$} \\
\hline $\mathrm{C}_{15} \mathrm{H}_{28}+15 \mathrm{CO}_{2} \rightarrow 30 \mathrm{CO}+14 \mathrm{H}_{2}$ & 2682.5 & (R.13) \\
\hline $\mathrm{C}_{19} \mathrm{H}_{38}+19 \mathrm{CO}_{2} \rightarrow 38 \mathrm{CO}+14 \mathrm{H}_{2}$ & 3500.9 & (R.14) \\
\hline $\mathrm{CH}_{4}+\mathrm{CO}_{2} \rightarrow 2 \mathrm{CO}+2 \mathrm{H}_{2}$ & 262.7 & (R.15) \\
\hline \multicolumn{3}{|l|}{ Carbon chain breakage } \\
\hline $\mathrm{C}_{15} \mathrm{H}_{28} \leftrightarrow 15 \mathrm{C}+14 \mathrm{H}_{2}\left(+\mathrm{CH}_{4}\right)$ & 119.8 & (R.16) \\
\hline $\mathrm{C}_{19} \mathrm{H}_{38} \leftrightarrow 19 \mathrm{C}+19 \mathrm{H}_{2}\left(+\mathrm{CH}_{4}\right)$ & 119.8 & (R.17) \\
\hline \multicolumn{3}{|l|}{ Carbon gasification } \\
\hline $\mathrm{C}+\mathrm{H}_{2} \mathrm{O} \rightarrow \mathrm{CO}+\mathrm{H}_{2}$ & 135.8 & (R.18) \\
\hline $\mathrm{C}+\mathrm{CO}_{2} \rightarrow 2 \mathrm{CO}$ & 172.8 & (R.19) \\
\hline \multicolumn{3}{|l|}{ Water-gas shift } \\
\hline $\mathrm{CO}+\mathrm{H}_{2} \mathrm{O} \leftrightarrow \mathrm{CO}_{2}+\mathrm{H}_{2}$ & 34.9 & (R.20) \\
\hline \multicolumn{3}{|l|}{ Air reactor } \\
\hline $\mathrm{Ni}+1 / 2 \mathrm{O}_{2}$ (air) $\rightarrow \mathrm{NiO}\left(+\mathrm{N}_{2}\right)$ & -234.3 & (R.21) \\
\hline \multicolumn{3}{|l|}{ Carbon combustion } \\
\hline $\mathrm{C}+\mathrm{O}_{2} \rightarrow \mathrm{CO}_{2}$ & -392.7 & (R.22) \\
\hline
\end{tabular}

\section{Process evaluated}

Fig. 3 shows a general diagram of the general system considered in this work for hydrogen production, which was composed by an a-CLR system, a WGS reactor and the heat exchangers. The sensible heat of the gas outlet streams at high temperature was used in the heat exchangers to evaporate and preheat the liquid and gas inlets streams. In addition a fuel molar flow of $1 \mathrm{~mol} / \mathrm{s}$ was considered as a basis for calculations.

The following assumptions were made:

- The system was at steady state.

- Heat losses were not considered.

- The temperature in the WGS reactor was $250{ }^{\circ} \mathrm{C}$.

- The gasses fed to the FR and AR were preheated up to $477^{\circ} \mathrm{C}$.

- All the gas outlet streams were cooled to $100^{\circ} \mathrm{C}$.

- The nickel oxide content of the oxygen carrier was $20 \mathrm{wt}$.\% supported on alumina.

- All oxygen fed to the AR reacts with the reduced oxygen carrier and, consequently, pure $\mathrm{N}_{2}$ was obtained at the $\mathrm{AR}$ outlet stream.

- The total water-to-fuel molar ratio in the global process was remained always constant, with the value given by the complete reforming reactions ((R.9) and (R.11)). Therefore, a $\mathrm{H}_{2} \mathrm{O} /$ fuel molar ratio of 30 and 38 were used for diesel and mineral oil, respectively. This feeding water can be distributed between the FR and the WGS reactors.

\section{Mass balance in the a-CLR system}

The mass balance was based on the oxygen transferred by the oxygen carrier at steady state operating conditions. The oxygen given by the air fed to the AR was equal to the oxygen taken by the oxygen carrier in the AR and equal to the oxygen reacted in the FR with the fuel:

$$
\begin{aligned}
& \text { Oxygen }_{\mathrm{air}, \mathrm{AR}}=\text { Oxygen }_{\mathrm{OC}, \mathrm{AR}}=\text { Oxygen }_{\mathrm{OC}, \mathrm{FR}} \\
& F_{\mathrm{O}_{2}, \text { in }} \Delta \mathrm{X}_{\mathrm{O}_{2}}=\frac{F_{\mathrm{S}} \mathrm{X}_{\mathrm{NiO}, \mathrm{ox}}}{\mathrm{M}_{\mathrm{NiO}}} \Delta \mathrm{X}_{\mathrm{S}}=F_{\mathrm{Fuel}} \frac{\mathrm{O}_{\mathrm{NiO}}}{\text { Fuel }}
\end{aligned}
$$

where $\mathrm{F}_{\mathrm{O}_{2} \text {,in }}$ is the molar flow of oxygen at the inlet of the AR, $\mathrm{M}_{\mathrm{NiO}}$ is the molecular weight of $\mathrm{NiO}, \mathrm{F}_{\mathrm{s}}$ is the oxygen carrier circulation flow-rate, $\mathrm{x}_{\mathrm{NiO}, \mathrm{ox}}$ is the $\mathrm{NiO}$ content of the oxygen carrier when it is fully oxidized, $\mathrm{F}_{\mathrm{Fuel}}$ is the molar flow of the fuel fed into the $\mathrm{FR}$, and $\mathrm{O}_{\mathrm{NiO}} /$ Fuel molar ratio is the amount of oxygen transferred by the oxygen carrier to the FR per mol of fuel fed. 
The oxygen conversion in the $\mathrm{AR}, \Delta \mathrm{X}_{\mathrm{O}_{2}}$, was defined as:

$\Delta \mathrm{X}_{\mathrm{O}_{2}}=\frac{\mathrm{F}_{\mathrm{O}_{2} \text {,in }}-\mathrm{F}_{\mathrm{O}_{2} \text {,out }}-\mathrm{F}_{\mathrm{CO}_{2} \text {,out }}}{\mathrm{F}_{\mathrm{O}_{2} \text {,in }}}$

where $\mathrm{F}_{\mathrm{O}_{2} \text {,out }}$ is the molar flow of oxygen at the outlet of the AR and $\mathrm{F}_{\mathrm{CO}_{2} \text {,out }}$ corresponds to the molar flow of $\mathrm{CO}_{2}$ produced by the combustion of the possible carbon formed in the FR ((R.16) and (R.17) for diesel and mineral oil).

The conversion variation in the oxygen carrier, $\Delta \mathrm{X}_{\mathrm{s}}$, was written as:

$\Delta \mathrm{X}_{\mathrm{S}}=\mathrm{X}_{\mathrm{AR}}-\mathrm{X}_{\mathrm{FR}}$

where $\mathrm{X}_{\mathrm{AR}}$ and $\mathrm{X}_{\mathrm{FR}}$ are the conversion of the oxygen carrier at the outlet of the AR and FR, respectively.

The composition of the gas produced in the FR was calculated assuming that the product gas was in thermodynamic equilibrium, using the method of minimization of the Gibbs free energy with the HSC Chemistry 6.1 software [24].

\section{Heat balance in the a-CLR system}

One of the main advantages of the CLR process is the possibility to reach autothermal conditions where no external heat is required for syngas $/ \mathrm{H}_{2}$ production. The heat balance for the CLR system was solved simultaneously to the mass balance to determine the conditions allowing autothermal operation. In this case,

$\Delta H_{\mathrm{CLR}}=\Delta \mathrm{H}_{\mathrm{FR}}+\Delta \mathrm{H}_{\mathrm{AR}}$

where $\Delta \mathrm{H}_{\mathrm{FR}}$ and $\Delta \mathrm{H}_{\mathrm{AR}}$ are the variation of enthalpy associated to all gases and solids inside the FR and AR respectively, and $\Delta \mathrm{H}_{\mathrm{CLR}}$ is the energy required to remove or give to the CLR system. If $\Delta \mathrm{H}_{\mathrm{CLR}}<0$ it means that there is excess of heat generated in the CLR system. On the contrary, if $\Delta \mathrm{H}_{\mathrm{CLR}}>0$ it means that extra heat is needed for the process, specifically for the endothermic reactions ((R.1-R.3), (R.6-R.20)) in the FR. The process reaches autothermal conditions when $\Delta \mathrm{H}_{\mathrm{CLR}}$ is equal to 0 , and it was designated as $\Delta \mathrm{H}_{\mathrm{a}-\mathrm{CLR}}$.

The variation of enthalpy was calculated as:

$\Delta \mathrm{H}_{\mathrm{j}}=\sum \mathrm{n}_{\mathrm{i}} \mathrm{h}_{\mathrm{i}}$

where $n_{i}$ is the number of moles and $h_{i}$ the enthalpy of each component, which is obtained according to:

$\mathrm{h}_{\mathrm{i}}=\mathrm{h}_{\mathrm{oi}}+\int_{298}^{\mathrm{T}} \mathrm{Cp}_{\mathrm{i}}(\mathrm{T}) \mathrm{dT}$

being $\mathrm{h}_{\mathrm{oi}}$ the standard enthalpy, $\mathrm{T}$ the operating temperature and $\mathrm{Cp}_{\mathrm{i}}$ the specific heat of each component.

Once the autothermal operating conditions were obtained for the CLR system, the mass and heat balances were done for the global process including the WGS reactor and the heat exchangers.

$\Delta \mathrm{H}_{G}=\Delta \mathrm{H}_{a-\mathrm{CLR}}+\Delta \mathrm{H}_{\mathrm{WGS}}+\sum \Delta \mathrm{H}_{\mathrm{HE}}$ where $\Delta \mathrm{H}_{\mathrm{WGS}}$ and $\Delta \mathrm{H}_{\mathrm{HE}}$ are the variation of enthalpy in the WGS reactor and those associated to each heat exchanger used in the process. It must be remembered that $\Delta \mathrm{H}_{\mathrm{a} \text {-CLR }}$ is zero.

\section{Results and discussion}

\section{Evaluation of the autothermal CLR system}

The mass and heat balances were done simultaneously to obtain the autothermal conditions in the CLR system (a-CLR) using diesel as fuel. The autothermal conditions avoiding carbon formation were first determined for different water-todiesel molar ratios in the FR, keeping constant the total waterto-diesel molar ratio (water fed into the FR and WGS reactors) to 30 .

Fig. 4 shows the $\mathrm{O}_{\mathrm{NiO}} /$ diesel molar ratios needed to reach the a-CLR system and the minimum value needed to avoid carbon formation as a function of the FR temperature. As an example, Fig. 4a shows the a-CLR system obtained for $\mathrm{H}_{2} \mathrm{O}$ / diesel molar ratio in the FR equal to 15 . Zone below the a-CLR line corresponds to a system where extra heat is needed for syngas production. On the contrary, in the zone above the aCLR, surplus heat is produced. In addition, shadow area represents conditions where carbon formation takes place.

Fig. $4 \mathrm{~b}$ shows the results with different $\mathrm{H}_{2} \mathrm{O}$ /diesel molar ratios in the FR: $0,5,15$ and 30 . These last two molar ratios are the required ones for the reforming reaction (R.8) and the complete reforming reaction (R.9), respectively.

It can be observed that a decrease of the FR temperature allows the use of lower $\mathrm{O}_{\mathrm{NiO}} /$ diesel molar ratios fed to the $\mathrm{FR}$ to reach the autothermal condition (continuous lines). The minimum operating temperature is limited by the carbon formation process (discontinuous lines) indicated by the dots. It must be remarked that it is impossible to reach the autothermal condition without carbon formation when no water was fed to the FR. This means that there is a minimum $\mathrm{H}_{2} \mathrm{O}$ / diesel molar ratio that allows working at autothermal conditions in the range of temperatures usually used in the FR of the CLR system. Otherwise, a $\mathrm{H}_{2} \mathrm{O}$ /diesel molar ratio of 30 in the FR allows working with any $\mathrm{O}_{\mathrm{NiO}} /$ diesel molar ratio without carbon formation at any temperature. However, it has to be considered that the reactions could be limited by the reaction rate when working at temperatures lower than $800{ }^{\circ} \mathrm{C}$. In addition, heat losses in industrial units account for values $\approx 10 \%$ of the heat evolved in the CLR process. This fact implies that more $\mathrm{O}_{\mathrm{NiO}} /$ Diesel is needed to reach autothermal conditions, and as consequence, less $\mathrm{H}_{2}$ is obtained. The same behavior above commented for diesel could be extrapolated for the operation with mineral oil or any other liquid fossil fuel.

\section{$\mathrm{H}_{2}$ production in the global process}

Based on the $\mathrm{O}_{\mathrm{NiO}} /$ diesel molar ratios that allow working at autothermal conditions with no carbon formation, mass and heat balances were done in the global $\mathrm{H}_{2}$ production process (a-CLR + WGS + heat exchangers) previously commented. Fig. 5 shows the variation of enthalpy and the total $\mathrm{H}_{2}$ 


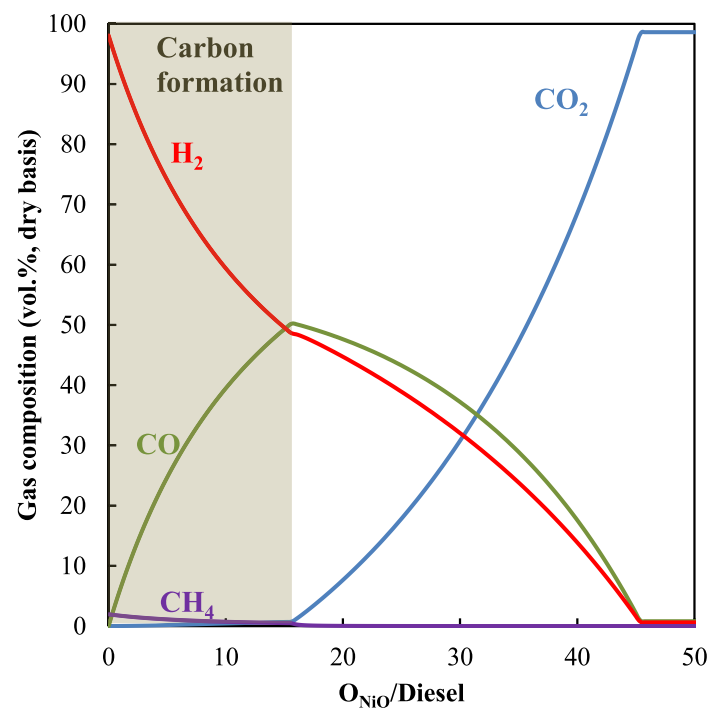

Fig. 2 - Gas composition in thermodynamic equilibrium as a function of the oxygen reacted in the FR per mol of diesel. $\mathrm{T}_{\mathrm{FR}}=900{ }^{\circ} \mathrm{C} . \mathrm{H}_{2} \mathrm{O} / \mathrm{Fuel}=0$.

production in the global process as a function of the FR temperature for three amounts of water fed to the FR: 5, 15, and 30.

It can be observed that there is an optimum FR temperature for which there is a maximum in the $\mathrm{H}_{2}$ production for each $\mathrm{H}_{2} \mathrm{O}$ /diesel molar ratio evaluated (see Fig. 5a). Operating temperatures below the optimum produced a decrease in the $\mathrm{H}_{2}$ production due to the presence of unconverted methane, which is formed as intermediate product in the decomposition reactions. Operating temperatures above the optimum produced a decrease in the hydrogen production because higher $\mathrm{O}_{\mathrm{NiO}} /$ diesel molar ratios are needed to reach autothermal conditions and therefore, there is a major contribution of the complete oxidation reactions ((R.1), (R.3-R.5)).

However, to reach the maximum $\mathrm{H}_{2}$ production it is necessary contribution of external energy (see Fig. 5b). In this case, to work at autothermal conditions in the global process is necessary to increase the temperature of the FR. At these conditions, the $\mathrm{H}_{2}$ production in the global process decreases and it is the same independently the $\mathrm{H}_{2} \mathrm{O}$ /diesel molar ratio used in the FR. It has to be considered that the total $\mathrm{H}_{2} \mathrm{O}$ /diesel molar ratio fed to the global process was kept always constant (30 for diesel operation). The difference relays in the different operating temperature needed in the $\mathrm{FR}$, being lower as the $\mathrm{H}_{2} \mathrm{O}$ /diesel molar ratio fed to the $\mathrm{FR}$ increases.

\section{$\mathrm{H}_{2}$ production using different liquid fuels}

The use of diesel or mineral oil in the a-CLR system exhibited a similar behavior, being the slight differences in the results due to the different stoichiometric of the reactions involved for each fuel.

In this section, for a better comparison among fuels, the results have been normalized per mol of carbon fed into the FR. Results previously obtained using ethanol (EtOH) as fuel [25] have been also included.

Fig. 6 shows the hydrogen production per mol of $\mathrm{C}$ fed to the FR as a function of the FR temperature using a $\mathrm{H}_{2} \mathrm{O} / \mathrm{C}_{\text {Fuel }}$ molar ratio in the FR corresponding to the complete reforming reaction ((R.9) and (R.11)). This ratio takes the values of 2 for diesel and mineral oil and 1.5 for EtOH.

It can be observed that the $\mathrm{H}_{2}$ produced per mol of $\mathrm{C}$, for a given temperature, is almost the same independently of the fossil fuel used. However, the $\mathrm{H}_{2}$ production was higher when using EtOH mainly due to the presence of oxygen in its

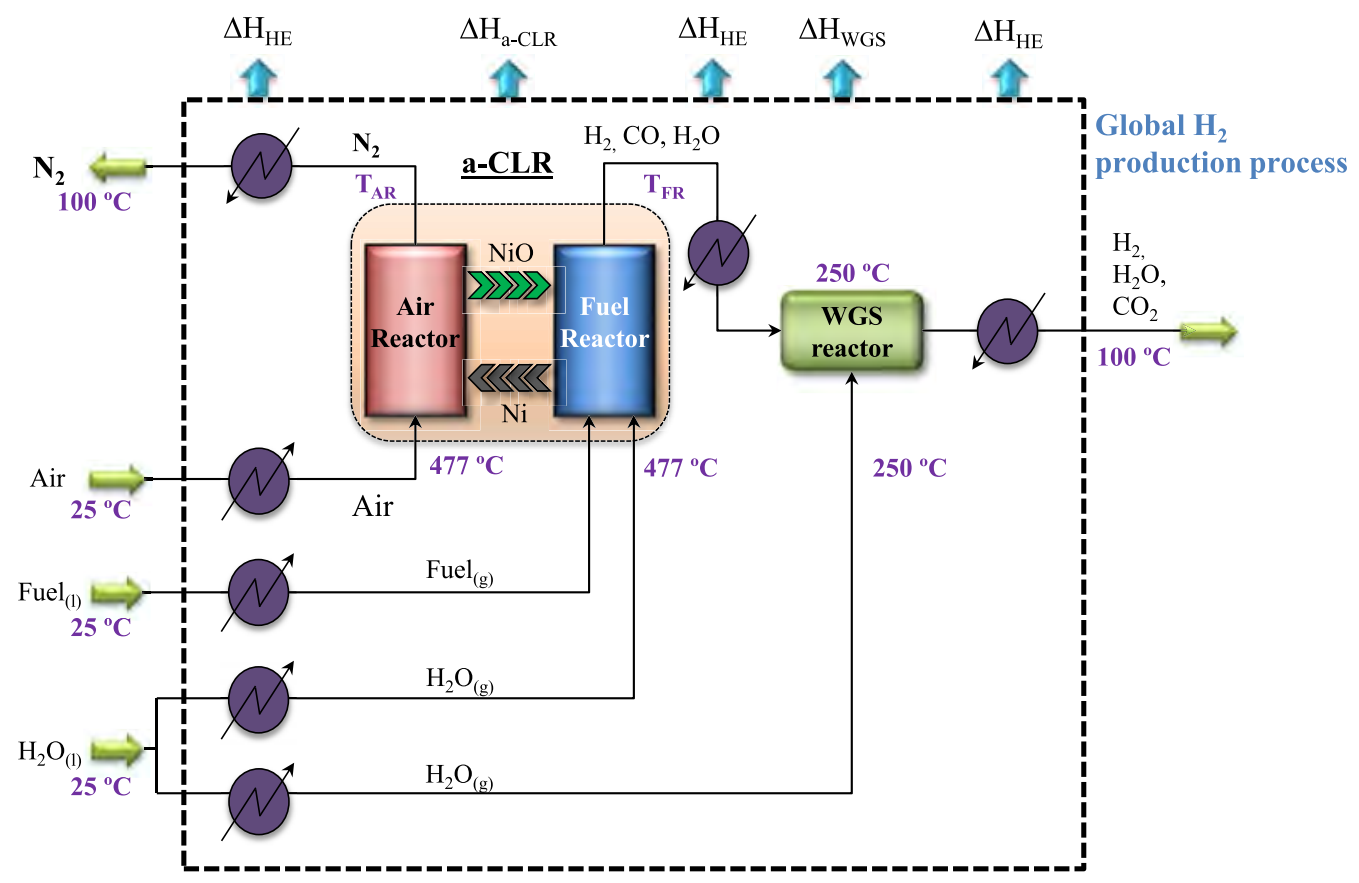

Fig. 3 - Global $\mathrm{H}_{2}$ production process with an integrated a-CLR system. 

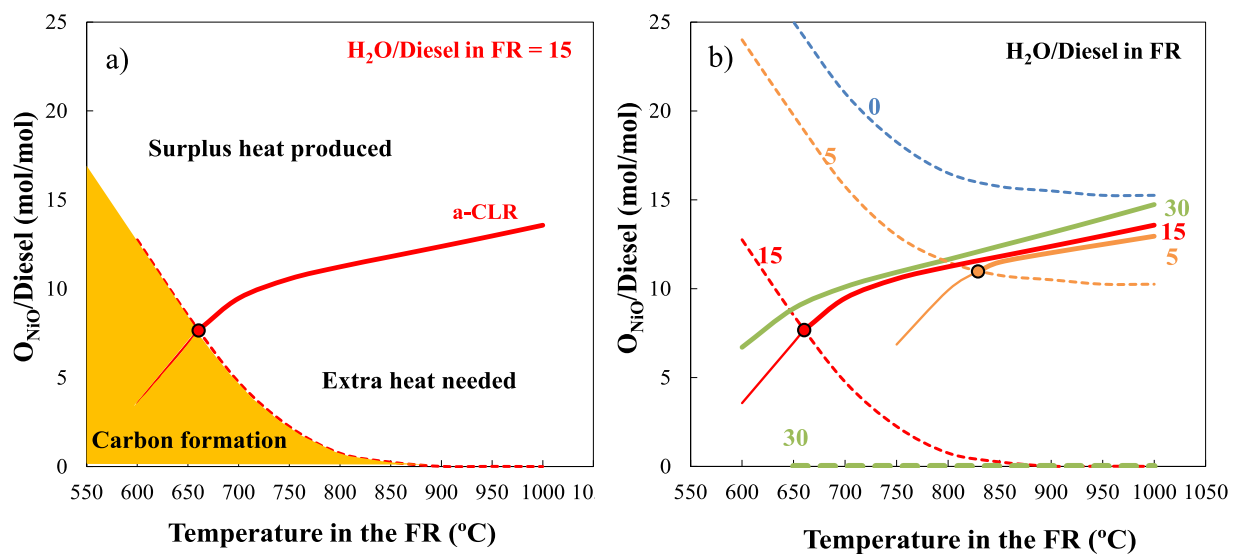

Fig. $4-\mathrm{T}_{\mathrm{FR}}$ and $\mathrm{O}_{\mathrm{NiO}} /$ diesel molar ratios that avoid carbon formation at autothermal conditions for different $\mathrm{H}_{2} \mathrm{O} /$ diesel molar ratios. a) $\mathrm{H}_{2} \mathrm{O} /$ diesel $=15$. b) $\mathrm{H}_{2} \mathrm{O} /$ diesel $=0-30$. Continuous lines: $\mathrm{O}_{\mathrm{Nio}} /$ diesel molar ratios at autothermal conditions for each $\mathrm{T}_{\mathrm{FR}}$. Discontinuous lines: minimum $\mathrm{O}_{\mathrm{NiO}} /$ diesel molar ratios that avoid carbon formation.

composition. Therefore, it can be concluded that the $\mathrm{H}_{2}$ production per mol of $\mathrm{C}$ in the autothermal global process is almost the same for any liquid fuel containing only $\mathrm{C}$ and $\mathrm{H}$ in its composition.

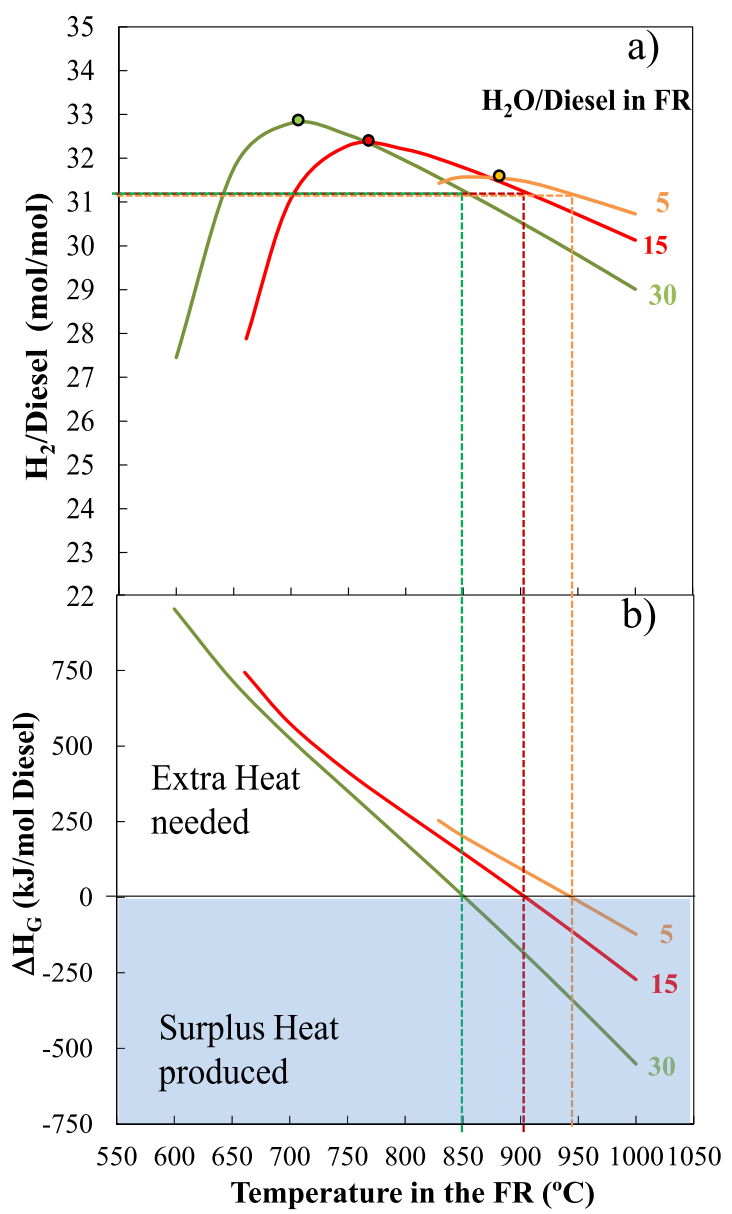

Fig. 5 - Effect of the $\mathrm{H}_{2} \mathrm{O}$ /diesel molar ratio on the global process as a function of the FR temperature. a) Global $\mathrm{H}_{2}$ production, and b) Global enthalpy balance, in the a-CLR system with no carbon formation. Dots $=$ maximum $\mathrm{H}_{2}$ production.
Experimental evaluation of the a-CLR system at low temperatures

The simulation has shown the existence of an optimum FR temperature that maximizes the $\mathrm{H}_{2}$ production for all fuels although this implies an external energy supply (see Fig. 5). However, it is possible that the syngas production could be limited by the reaction rates at the low optimum temperatures. As a consequence, the assumptions of complete fuel conversion or gas composition in thermodynamic equilibrium used in the simulation would not be valid.

To check the validity of the above assumptions, new experiments at low temperatures $\left(600-850^{\circ} \mathrm{C}\right)$ were carried out in a CLR prototype, ICB-CSIC-liq1, using diesel and ethanol as fuels. More information about the prototype design and operation can be found elsewhere [17]. A Ni-based material, $\mathrm{NiO} 18-\alpha \mathrm{Al}_{2} \mathrm{O}_{3}[11,17]$ was used as oxygen carrier for the tests.

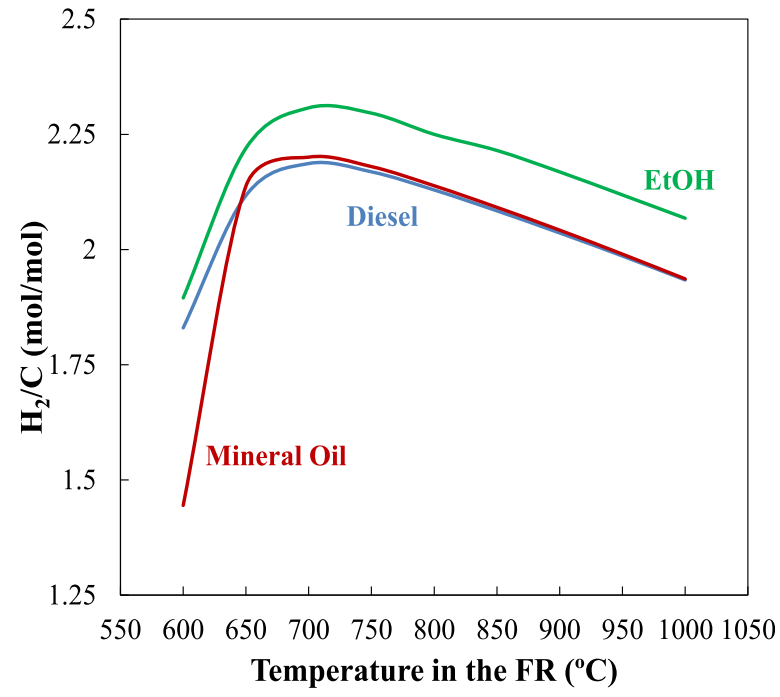

Fig. $6-\mathrm{H}_{2}$ production per mol of $\mathrm{C}$ fed to the FR as a function of the FR temperature using different fuels. $\mathrm{H}_{2} \mathrm{O}$ / $\mathrm{C}_{\mathrm{EtOH}}$ molar ratio $=1.5, \mathrm{H}_{2} \mathrm{O} / \mathrm{C}_{\text {diesel }}$ and $\mathrm{H}_{2} \mathrm{O} / \mathrm{C}_{\text {mineral oil }}$ molar ratios $=2$ in the $F R$. 
Each point evaluated corresponds to $60 \mathrm{~min}$ at steady state operation. The NiO content of this oxygen carrier is slightly different from the theoretical value used in this work for calculations. However, it has been proved in a previous work that small differences in the $\mathrm{NiO}$ content does not affect $\mathrm{H}_{2}$ production if solids circulation rate is maintained constant $[17,25]$.

Fig. 7 shows the experimental $\mathrm{H}_{2}$ and $\mathrm{CH}_{4}$ produced per mol of carbon in the CLR prototype for the two liquid fuels used at autothermal conditions, as well as the $\mathrm{O}_{\mathrm{NiO}} / \mathrm{C}_{\text {fuel }}$ molar ratio used in each case. The $\mathrm{H}_{2} \mathrm{O}$ /fuel molar ratio of 30 and 3 were used for the diesel and ethanol, respectively, in the FR without any other $\mathrm{H}_{2} \mathrm{O}$ addition to the WGS reactor. These molar ratios correspond to $\mathrm{H}_{2} \mathrm{O} / \mathrm{C}_{\text {Diesel }}=2$ and $\mathrm{H}_{2} \mathrm{O} / \mathrm{C}_{\mathrm{EtOH}}=1.5$. Lines corresponding to thermodynamic equilibrium data have been also included in the Figure.

The experimental results confirmed the presence of the maximum in the $\mathrm{H}_{2}$ production fed into the FR (Fig. 7a) at temperatures near to the given by the simulation data,
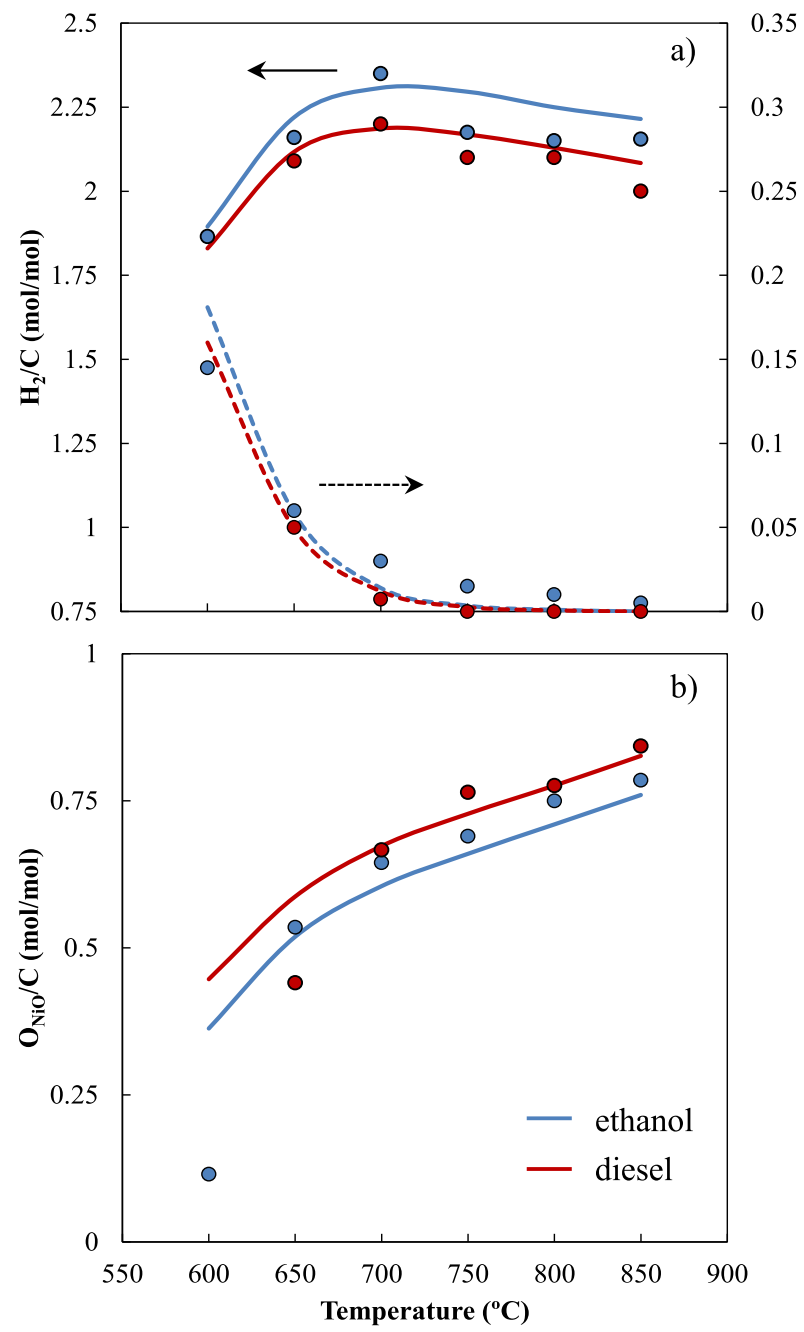

Fig. 7 - Experimental results using diesel and ethanol as fuel in a continuous CLR unit as a function of the FR temperature with the $\mathrm{NiO} 18-\alpha \mathrm{Al}_{2} \mathrm{O}_{3}$ oxygen carrier. $\mathrm{H}_{2} \mathrm{O}$ / $\mathrm{EtOH}=3, \mathrm{H}_{2} \mathrm{O} /$ diesel $=30$ in the $\mathrm{FR}$. a) $\mathrm{H}_{2}$ production and $\mathrm{CH}_{4}$ concentration per mol of carbon in the fuel. b) $\mathrm{O}_{\mathrm{NiO}} /$ $\mathrm{C}_{\text {fuel }}$ molar ratio. $\sim 700-750^{\circ} \mathrm{C}$ for both diesel and ethanol. It can be seen that the $\mathrm{CH}_{4}$ concentration increased as the temperature in the FR decreased, being especially important at temperatures below the optimum (see Fig. 7a). The presence of residual methane produced during fuel decomposition at these low operating temperatures confirms the reasons initially given by the simulation data. Finally, it must be remarked that in all tests complete fuel conversion was reached and the gas composition at the outlet of the FR were in thermodynamic equilibrium. Only at temperatures lower than $650{ }^{\circ} \mathrm{C}, \mathrm{CO}_{2}$ was detected at the AR gas outlet stream, even though carbon formation should not be formed according to the theoretical predictions. The difference between the experimental and theoretical $\mathrm{O}_{\mathrm{NiO}} / \mathrm{C}_{\text {fuel }}$ molar ratio obtained at these low temperatures corresponds to the amount of oxygen that is reacting with the carbon formed in the FR and detected as $\mathrm{CO}_{2}$ in the AR gas outlet stream.

\section{Conclusions}

This work shows the behavior of an autothermal CLR system and the $\mathrm{H}_{2}$ production with the autothermal operating conditions in a global system, which was composed by the a-CLR process, heat exchangers and a WGS, using diesel and mineral oil as fuels.

It was determined that there is a minimum operational FR temperature to avoid carbon formation, which decreased with increasing the $\mathrm{H}_{2} \mathrm{O} /$ Fuel molar ratio fed into the FR.

It was found that it is possible to obtain the same amount of hydrogen per mol of fuel at autothermal conditions in the global process independently if the same amount of water was added into the FR or distributed into the FR and the WGS reactor.

It was also observed that there is an optimum FR temperature for which there is a maximum $\mathrm{H}_{2}$ production in an a-CLR system, although to reach this FR temperature external heat is required. The presence of this maximum was experimentally demonstrated in a CLR prototype using diesel and ethanol as fuel.

The hydrogen production per mol of $\mathrm{C}$ in the autothermal global process was almost the same for diesel and mineral oil and lower than the obtained using ethanol due to the presence of oxygen in its composition.

\section{Acknowledgements}

This work is partially supported by the Spanish Ministry for Science and Innovation (MICINN project ENE2011-26354), by European Regional Development Fund (ERDF) and by the Government of Aragón (Spain, DGA ref. T06).

\section{Nomenclature}

$\mathrm{Cp}_{\mathrm{i}} \quad$ specific heat of each component, $\mathrm{kJ} / \mathrm{mol} \mathrm{K}$ $\mathrm{H}_{2} \mathrm{O} /$ Fuel molar ratio of water injected per mol of fuel fed (-) $\mathrm{F}_{\mathrm{s}} \quad$ oxygen carrier circulation flow-rate, $\mathrm{kg} / \mathrm{s}$ $F_{\text {Fuel }} \quad$ molar flow of fuel fed to the FR, mol/s 
$\mathrm{F}_{\mathrm{O}_{2} \text {,in }} \quad$ molar flow of oxygen at the inlet of the AR, mol/s

$\mathrm{F}_{\mathrm{O}_{2} \text {,out }}$ molar flow of oxygen at the outlet of the $\mathrm{AR}, \mathrm{mol} / \mathrm{s}$

$\mathrm{F}_{\mathrm{CO}_{2} \text {,out }}$ molar flow of $\mathrm{CO}_{2}$ at the outlet of the $\mathrm{AR}, \mathrm{mol} / \mathrm{s}$

$h_{i} \quad$ enthalpy of each component, $\mathrm{kJ} / \mathrm{mol}$

$\mathrm{h}_{\mathrm{oi}} \quad$ standard enthalpy of each component, $\mathrm{kJ} / \mathrm{mol}$

$\mathrm{M}_{\mathrm{NiO}} \quad$ molecular weight of $\mathrm{NiO}$, wt.\%

$\mathrm{n}_{\mathrm{i}} \quad$ number of moles of each component, mol

$\mathrm{O}_{\mathrm{NiO}} /$ Fuel moles of oxygen transferred by the oxygen carrier to the Fuel reactor per mol of fuel fed

$\mathrm{T} \quad$ operating temperature, ${ }^{\circ} \mathrm{C}$

$\mathrm{T}_{\mathrm{AR}} \quad$ temperature in the Air reactor, ${ }^{\circ} \mathrm{C}$

$\mathrm{T}_{\mathrm{FR}} \quad$ temperature in the Fuel reactor, ${ }^{\circ} \mathrm{C}$

$\mathrm{X}_{\mathrm{AR}}$ conversion of the oxygen carrier at the outlet of the AR

$\mathrm{X}_{\mathrm{FR}} \quad$ conversion of the oxygen carrier at the outlet of the FR

$\mathrm{x}_{\mathrm{NiO}, \mathrm{ox}} \mathrm{NiO}$ contents of the complete oxidized oxygen carrier

$\Delta \mathrm{H}_{\mathrm{AR}} \quad$ variation of enthalpy inside the $\mathrm{AR}, \mathrm{kJ} / \mathrm{mol}$ fuel

$\Delta \mathrm{H}_{\mathrm{CLR}} \quad$ variation of enthalpy in the CLR process, $\mathrm{kJ} / \mathrm{mol}$ fuel

$\Delta \mathrm{H}_{\mathrm{FR}} \quad$ variation of enthalpy inside the $\mathrm{FR}, \mathrm{kJ} / \mathrm{mol}$ fuel

$\Delta \mathrm{H}_{\mathrm{G}} \quad$ variation of enthalpy in the global system, $\mathrm{kJ} / \mathrm{mol}$ fuel

$\Delta \mathrm{H}_{\mathrm{HE}} \quad$ variation of enthalpy associated to each heat exchanger, $\mathrm{kJ} / \mathrm{mol}$ fuel

$\Delta H_{\text {WGS }}$ variation of enthalpy associated to the WGS reactor, $\mathrm{kJ} / \mathrm{mol}$ fuel

$\Delta \mathrm{X}_{\mathrm{O}_{2}} \quad$ variation in the oxygen conversion

$\Delta \mathrm{X}_{\mathrm{S}} \quad$ variation of the oxygen carrier conversion

\section{R E F E R E N C E S}

[1] U. S. Energy Information Administration (EIA), Annual Energy Outlook 2015 with projections to 2040.

[2] Deng C, Pan H, Li Y, Zhou Y, Feng X. Comparative analysis of different scenarios for the synthesis of refinery hydrogen network. Appl Therm Eng 2014;70:1162-79.

[3] Jiao Y, Su H, Hou W. Improved optimization methods for refinery hydrogen network and their applications. Control Eng Pract 2012;20:1075-93.

[4] Cruz FE, de Oliveira S. Petroleum refinery hydrogen production unit: exergy and production cost evaluation. Int J Thermodyn 2008;11:187-93.

[5] Damen K, van Troost M, Faaij A, Turkenburg W. A comparison of electricity and hydrogen production systems with $\mathrm{CO}_{2}$ capture and storage. Part A: review and selection of promising conversion and capture technologies. Prog Energy Combust Sci 2006;32:215-46.

[6] Fan LS, Zeng L, Wang W, Luo S. Chemical looping processes for $\mathrm{CO}_{2}$ capture and carbonaceous fuel conversion-prospect and opportunity. Energy Environ Sci 2012;5:7254-80.

[7] Zhao M, Minett AI, Harris T. A review of techno-economic models for the retrofitting of conventional pulverized-coal power plants for post-combustion capture (PCC) of $\mathrm{CO}_{2}$. Energy Environ Sci 2013;6:25-40.

[8] Adánez J, Abad A, García-Labiano F, Gayán P, de Diego LF. Progress in chemical-looping combustion and reforming technologies. Prog Energy Combust Sci 2012;38:215-82.
[9] Applications of chemical-looping combustion with capture of $\mathrm{CO}_{2}$. In: Mattisson T, Lyngfelt A, editors. Proceedings of the 2nd Nordic minisymposium on carbon dioxide capture and storage, Göteborg, Sweden; 2001.

[10] Rydén M, Lyngfelt A, Mattisson T. Synthesis gas generation by chemical-looping reforming in a continuously operating laboratory reactor. Fuel 2006;85:1631-41.

[11] Gayán P, Dueso C, Abad A, Adánez J, de Diego LF, GarcíaLabiano F. NiO/ $/ \mathrm{Al}_{2} \mathrm{O}_{3}$ oxygen carriers for chemical-looping combustion prepared by impregnation and depositionprecipitation methods. Fuel 2009;88:1016-23.

[12] Rydén M, Lyngfelt A, Mattisson T. Chemical-looping combustion and chemical-looping reforming in a circulating fluidized-bed reactor using Ni-based oxygen carriers. Energy Fuel 2008;22:2585-97.

[13] Ortiz M, Abad A, de Diego LF, García-Labiano F, Gayán P, Adánez J. Optimization of hydrogen production by chemicallooping auto-thermal reforming working with Ni-based oxygen-carriers. Int J Hydrogen Energy 2011;36:9663-72.

[14] Wang K, Dou B, Jiang B, Zhang Q Li M, Chen H, et al. Effect of support on hydrogen production from chemical looping steam reforming of ethanol over Ni-based oxygen carriers. Int J Hydrogen Energy 2016;41:17334-47.

[15] Jiang B, Dou B, Wang K, Zhang C, Song Y, Chen H, et al. Hydrogen production by chemical looping steam reforming of ethanol using $\mathrm{NiO} / \mathrm{montmorillonite}$ oxygen carriers in a fixed-bed reactor. Chem Eng J 2016;298:96-106.

[16] Wang K, Dou B, Jiang B, Song Y, Zhang C, Zhang Q, et al. Renewable hydrogen production from chemical looping steam reforming of ethanol using xCeNi/SBA-15 oxygen carriers in a fixed-bed reactors. Int J Hydrogen Energy 2016;41:12899-909.

[17] García-Labiano F, García-Díez E, de Diego LF, Serrano A, Abad A, Gayán $\mathrm{P}$, et al. Syngas/ $\mathrm{H}_{2}$ production from bioethanol in a continuous chemical-looping reforming prototype. Fuel Process Technol 2015;137:24-30.

[18] de Diego LF, Ortiz M, García-Labiano F, Adánez J, Abad A, Gayán P. Hydrogen production by chemical-looping reforming in a circulating fluidized bed reactor using Nibased oxygen carriers. J Power Sources 2009;192:27-34.

[19] Trevisanut C, Mari M, Millet J-MM, Cavani F. Chemical-loop reforming of ethanol over metal ferrites: an analysis of structural features affecting reactivity. Int J Hydrogen Energy 2015;40:5264-71.

[20] Dou B, Song Y, Wang C, Chen H, Yang M, Xu Y. Hydrogen production by enhanced-sorption chemical looping steam reforming of glycerol in moving-bed reactors. Appl Energy 2014;130:342-9.

[21] Moldenhauer P, Rydén M, Mattisson T, Lyngfelt A. Chemicallooping combustion and chemical-looping reforming of kerosene in a circulating fluidized-bed $300 \mathrm{~W}$ laboratory reactor. Int J Greenh Gas Control 2012;9:1-9.

[22] Lea-Langton A, Zin RM, Dupont V, Twigg MV. Biomass pyrolysis oils for hydrogen production using chemical looping reforming. Int J Hydrogen Energy 2012;37:2037-43.

[23] Barin I. Thermochemical data of pure substances. Weinheim: Wiley-VCH; 2004.

[24] HSC Chemistry 6.1. Chemical reaction and equilibrium software with thermochemical database and simulation module. Pori, Finland: Oututec Res Oy; 2008.

[25] García-Díez E, García-Labiano F, de Diego LF, Abad A, Gayán P, Adánez J, et al. Optimization of hydrogen production with $\mathrm{CO}_{2}$ capture by autothermal chemicallooping reforming using different bioethanol purities. Appl Energy 2016;169:491-8. 